Document downloaded from:

http://hdl.handle.net/10251/75132

This paper must be cited as:

Pastor Soriano, JV.; García Oliver, JM.; Nerva, J.; Giménez, B. (2011). Fuel effect on the liquid-phase penetration of an evaporating spray under transient diesel-like conditions. Fuel. 90(11):3369-3381. doi:10.1016/j.fuel.2011.05.006.

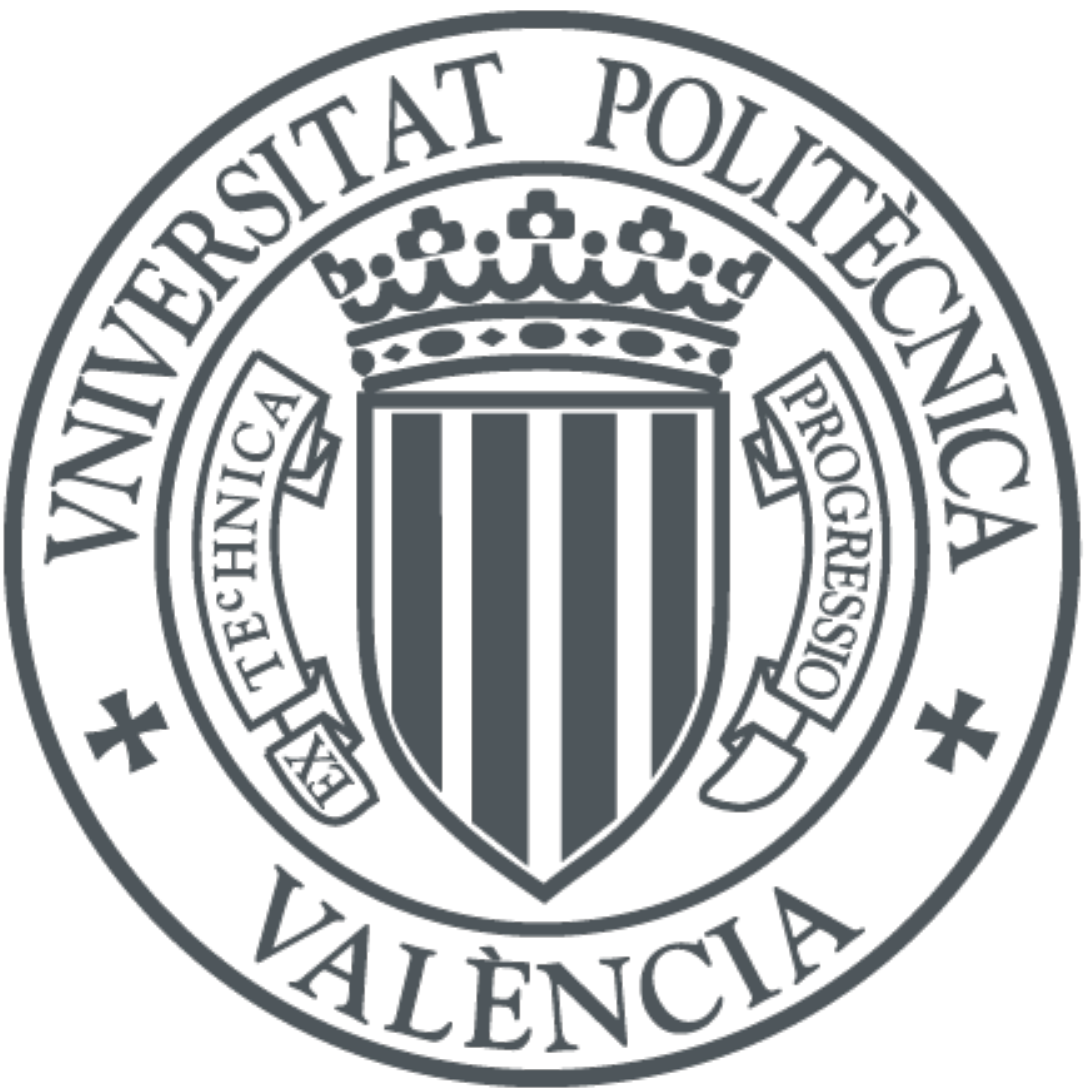

The final publication is available at

http://dx.doi.org/10.1016/j.fuel.2011.05.006

Copyright Elsevier

Additional Information 


\title{
Fuel Effect on the Liquid-Phase Penetration of an Evaporating Spray Under Transient Diesel-like Conditions
}

\author{
J.V. Pastor ${ }^{a *}$, J.M. García-Oliver ${ }^{a}$, J.-G. Nerva ${ }^{a}$, B. Giménez ${ }^{b}$ \\ ${ }^{a}$ CMT-Motores Térmicos. Universitat Politècnica de València \\ Camino Vera $s / n$ - 46022 Valencia, Spain. \\ ${ }^{b}$ Department of Energy and Fluid Mechanics Engineering. University of Valladolid. \\ Paseo del Cauce s/n, 47011 Valladolid, Spain.
}

\begin{abstract}
Measurements of the maximum liquid-phase penetration have been performed injecting five different fuels through a single-hole nozzle in an optical engine under a large set of thermodynamic and injection conditions. The focus of this paper is twofold. First, it pretends to study fuel physical properties on liquid-phase fuel penetration. The choice made on Fischer-Tropsch diesel (FTD) and biodiesel fuels has been highly motivated by their potential to be, at short or middle term, possible substitutes to the conventional diesel fuel. Extensive characterization of fuel physical and chemical properties under ambient conditions are provided and related to the liquid-phase penetration in order to provide an accessible tool to predict liquid spray behavior based on cheap, off-engine measurements. Fischer-Tropsch fuels appeared to be the easiest to vaporize while biodiesel blends were getting always harder to vaporize as the Rapeseed Methyl Ester $(R M E)$ rate was increased. The second
\end{abstract}

\footnotetext{
*Corresponding author

Email address: jpastor@mot.upv.es (J.V. Pastor ${ }^{a}$ )
} 
objective of this work is to study the time-response of liquid-phase penetration when subjected to density and temperature variations. Injections of $8 \mathrm{~ms}$ at three different pressures have been performed in transient diesellike conditions with density and temperature time derivatives up to 2000 $\mathrm{kg} \cdot \mathrm{m}^{-3} \cdot \mathrm{s}^{-1}$ and $20000 \mathrm{~K} . \mathrm{s}^{-1}$. In most cases, the spray appeared to closely follow predictions made from empirical models built out of steady-state air conditions, leading to the conclusion of an instantaneous adjustment of the spray to its environment, validating: (1) the hypothesis made in 1D spray models; (2) the use of empirical models in unsteady-state environment when obtained under steady-state conditions.

Key words: diesel engine, biodiesel, spray, Fischer-Tropsch, fuel properties, liquid length, correlation, unsteady conditions.

\section{Introduction}

2 During the past two decades, research on the effect of fuel properties 3 may not have received fervent interest by the automotive industry, perhaps 4 due to the long-standing establishment of conventional diesel and the lack 5 of viable alternative solutions. Although the studies available on the subject 6 represent precious information for the validation of spray modeling hypoth7 esis $[1,2,3,4]$, most of the research effort has been channeled into new 8 combustion concepts using complex injection strategies and high EGR levels 9 in order to reduce both $N O_{X}$ and $P M$. More recently, worldwide environmental agencies have been inciting car constructors to find alternatives to 11 the exhaustible fossil fuel for a better sustainability of energy management 12 [5]. In this ambitious framework, biofuels and synthetic fuels represent an 
interesting perspective, at least at short and middle term, for their capacity to be directly implanted in the actual car park with no major change of the engine design. Their effect on combustion efficiency and emissions is the result of a complex succession of physical and chemical processes [6]. This study pretends to understand and assess which are the physical mechanisms involved in the introduction of alternative fuels. For this objective, various off-engine measurements have been performed on the five fuels before their injection through a $82 \mu m$-single-hole nozzle, in an optical engine [7] fed with pure nitrogen. The visualization of their respective maximum liquid-phase penetration has been realized under a large set of operating conditions, including a sweep of air temperature at constant density, a sweep of air density at constant temperature and three different injection pressures have been performed for each fuel. High-speed imaging of the spray shadow left on a highly lit background has been processed to measure the maximum liquid-phase penetration as defined by Dec and Siebers in $[9,10]$. In the first instance, liquid length results and air conditions have been time-averaged as in $[11,12,13]$ and discussed. In a second instance, unsteadiness of air density and air temperature during the fuel injection has been used as a way to increase the number of experimental data and consequently the reliability of statistics. For each image and so for each instant of the $8 \mathrm{~ms}$ injection event, its corresponding air temperature and density were associated. Apart from presenting clear advantages on the statistical point of view [14], these results permitted to conclude on spray reactivity when submitted to variations of ambient density and temperature. 


\section{Experimental Setup}

\subsection{Fuels}

Five different fuels have been selected for their capacity and their potential to be used in a diesel engine with no fundamental redesign of the engine whilst having significant differences in both physical and chemical properties. The first three fuels are widely known in the literature under the generic label "first generation biodiesels". Indeed, they are partially or entirely issued from cereal feedstock. RME (Rapeseed Methyl Ester) is a fuel issued from the transesterification reaction between rape oil and methanol. B05 and B30 are blends of fossil diesel with respectively 5 and 30 mass percentage of the same $R M E$.

[Table 1 about here.]

These three fuels have been previously used by the authors in a multi-hole injector configuration under both reactive and non-reactive environments $[12,13]$. Finally, the two last fuels are Fischer-Tropsch fuels issued from gas, coal or biomass liquefaction and will be referred as FT1 and FT2 in the following study. Various measurements of fuel properties have been performed off-engine. Thermodynamic properties, energetic content and equivalent formula have been measured following $A S T M$ standards and are summarized in Table 2. Results show that by increasing $R M E$ rate in biodiesel fuels, both density and viscosity increase as well, whereas $L H V$ reduces because of the increasing oxygen content. Both Fischer-Tropsch fuels have a lower density compensated by a higher energetic content, which is an important data under a marketing point of view, since the energetic content of one 
liter is pretty much the same between all these fuels. FT2 is singular by its very low viscosity and its small extra oxygen content. Comparative trends in fluid-mechanics properties were also observed in [15] for a similar selection of fuels. Chemical equivalent formulas have been measured using gas chromatography-FID and are also provided in Table 1. They appear to be close to heptadecane $\left(\mathrm{C}_{17} \mathrm{H}_{36}\right)$ and dodecane $\left(\mathrm{C}_{12} \mathrm{H}_{26}\right)$ formulas respectively for FT1 and FT2 while RME's closest pure surrogate could be methyl-oleate $\left(\mathrm{C}_{19} \mathrm{H}_{36} \mathrm{O}_{2}\right)$. Distillation curves have been measured under the ASTMD86 standard. Besides, a weighing scale was measuring the collected mass simultaneously, in order to detect a possible shift between mass and volume recovery percentage. Results are presented in Figure 1. On one hand, RME and FT2 appear to have relatively flat distillation curves, which is the witness of their homogeneity and their similitude to their corresponding surrogate. On the other hand, B05, B30 and FT1 have similar trends in evaporation under atmospheric pressure, starting from values close to FT2 and ending to values close to RME. Consequently, it can be expected that B05, B30 and FT1's lightest fractions are molecules heavier than FT2 $\left(\mathrm{C}_{12} \mathrm{H}_{25} \mathrm{O}_{0.2}\right)$ and that their heaviest fractions are close to $R M E$ 's molecular weight $\left(\mathrm{C}_{18.95} \mathrm{H}_{35.2} \mathrm{O}_{2}\right)$. For $B 05$ and B30, their RME content is expected to correspond to this heavy fraction. No significative differences can be observed on the comparison between mass and volume percentage recovery. This attests that no important variations of density exist among the proper components of each fuel.

[Figure 1 about here.]

While the fuel was getting to the temperature of its first boiling point, an important volume expansion has been observed, measured and traduced to 
density as a function of temperature, considering mass conservation. Results plotted in Figure 2 show linear trends with high $R^{2}$. Coefficients for a linear regression $\rho_{f}=B+A . T_{f}$ have been summarized in Table 2. ASTM D1298 measurements have been added to the plot as well for illustration, but have not been used in the linear regressions for data consistency. A small offset exists between the ASTM measurements and what would be the corresponding measurement by volume at $289 \mathrm{~K}$. Such volume measurements are not as accurate as the ASTM D1298 but authors believe that the trend is reliable enough to be used as $\rho_{f}=\rho_{A S T M D 1298}+A$.( $\left(T_{f}-289\right)$. It can be observed how these coefficients $(A)$ are all slightly inferior to the value for the US diesel $\sharp 2$ (0.9) referred by Siebers in [16].

[Figure 2 about here.]

[Table 2 about here.]

\subsection{Hot Spray Test Rig}

[Figure 3 about here.]

Tests have operated in a rapid cycling machine described in [7] and illustrated in Figure 3. This facility is based on a modified loop-scavenged single cylinder 2-stroke direct injection diesel engine with three liter displacement and low rated rotational speed $(500 \mathrm{rpm})$. This apparatus makes optical studies on free sprays under inert or reactive diesel-like thermodynamic conditions possible. Intake and exhaust being handled by transfers on the liner, optical access to the high-pressure chamber can be easily achieved through the cylinder head which encloses a cylindrical combustion chamber large enough 
to avoid spray impingement against engine walls. This chamber has an upper port where a single-hole injector equipped with a $82 \mu \mathrm{m}$ conical nozzle is mounted, and four lateral orthogonal accesses. One of theses accesses is used by a pressure transducer whereas the three other ones are equipped with oval-shaped quartz windows, $88 \mathrm{~mm}$ long, $37 \mathrm{~mm}$ large, and $28 \mathrm{~mm}$ thick. Although the use of a single-hole injector may produce faster pressure build-up in the nozzle sac-hole, a faster needle lift and a higher pressure at full needle lift [8], it still presented certain benefits compared to the multihole one previously used by the authors in the same facility [12]. First, it impeded spray-to-spray interaction (aerodynamic + thermodynamic) and its position relative to the chamber allowed a much larger field for spray development $(80 \mathrm{~mm}$ vs. $35 \mathrm{~mm})$. Above all, the mass injected was strongly limited despite the performing of relatively long injections, so that no effect on thermodynamic conditions alteration has been detected on the pressure trace. Indeed, in [12], the use of a multi-hole injector with $130 \mu \mathrm{m}$ nozzle hole had led the authors to consider the ambient temperature reduction due to fuel vaporization energetic consumption. The window for time-averaging had to be limited in order to consider steady-state environment. More details about the nozzle and injection settings can be found in Figure 4. For this study, the inert configuration has been set by feeding the engine with pure nitrogen so that any reaction due to air oxygen content was avoided. Consequently, outcomes relative to this work concern exclusively the physical processes associated to fuel injection, atomization, mixing, heat transfer and vaporization. The rig has been operated under a skip fire mode, i.e. one injection event occurs every 20 engine cycles. This strategy is commonly 
used to minimize windows fouling and to let the system filter the air and then avoid air saturation with vaporized fuel.

[Figure 4 about here.]

\subsection{Operating Conditions}

[Figure 5 about here.]

The test matrix includes five different engine operating conditions which have been selected in order to realize a sweep of three $T_{\max }$ at constant $\rho_{\max }\left(26 \mathrm{~kg} \cdot \mathrm{m}^{-3}\right)$ and a sweep of three $\rho_{\max }$ at constant $T_{\max }(800 \mathrm{~K})$ as shown in Figure 5. The five operating conditions have been labeled NO, $L T, H T, L D, H D$, standing respectively for NOminal, Low Temperature, High Temperature, Low Density and High Density air setup. The five fuels have been injected at three pressure levels (50, 100 and $150 \mathrm{MPa}$ ). The injector was triggered at $-16^{\circ} A T D C$ and energized during $8 \mathrm{~ms}(\approx 24 C A D$ depending on the instantaneous speed close to the TDC of each operating condition). All information relative the the injector has been summarized in Table 3. Each test has been repeated 10 times leading to a total number of injections equal to 750 for the whole study ( 5 fuels $\mathrm{x} 5 O C \times 3 P_{i n j} \mathrm{x}$ $10 i n j$.$) . To determine the exact intake air condition required by the test$ plan, an accurate characterization of the engine has been performed over 35 points covering its full range of operating conditions. Thermodynamic conditions have been calculated from the cylinder pressure using a first-law thermodynamic analysis considering blow-by, heat transfer and mechanical stress. By a succession of interpolations, the exact air intake conditions for the test plan are then calculated. A double-check is performed by setting 
the resulting values to the engine and the reiteration of the same first-law analysis. Results of the engine characterization can be found in Table 3 and intake conditions to carry out the test plan are indicated in Figure 5. The resulting temperature and densities in the close to TDC region are plotted in Figure 6.

[Figure 6 about here.]

[Table 3 about here.]

\subsection{Optical Setup and Image Processing}

Diffused back-light images have been taken at $8000 \mathrm{fps}$. Illumination was provided by two $150 \mathrm{~W}$ quartz-halogen illuminators (Dolan-Jenner PL800), supplied by $8 \mathrm{~mm}$ optic fiber bundles positioned at $60 \mathrm{~mm}$ from the diffuser dispensing an illumination of $330 \mathrm{~W} \cdot \mathrm{m}^{-2}$. The optical setup is represented in Figure 3. Exposure time of the high-speed CMOS camera (Photron FastcamUltima APX) has been limited to $25 \mu \mathrm{s}$. Imaging has been kept to this relatively low speed in order to keep a reasonable spatial resolution of 8.9 pixels $/ \mathrm{mm}$. Camera bit depth of 10 bits allowed a good discretization of digital levels for subsequent image segmentation. The camera was triggered by a TTL signal synchronized with the injector start of energizing ( $S O E$ ). Each injection event was documented by 100 pictures, accommodating a 12.5 $m s$ acquisition time from the $S O E$.

Images of the spray have been processed with a purpose-made $\mathrm{C}++$ code described in $[12,17,18]$. Figure 8 shows two of these processing steps. After a background subtraction (a), a threshold is calculated based on a statistical analysis of each image background [12] and used for image segmentation. 
Connectivity to the spray center of mass removes any imperfection left on the segmented image. The distance between the injector tip and the front part of the detected boundary is considered to be the maximum liquid-phase penetration (b).

\section{Analysis Methodology}

As commented in the introduction, data have been processed in two different ways to assess physical processes associated to engine operation and fuel physical properties. After a short theoretical review, the approach of the statistical analysis and its relation to the experiment will be presented.

[Figure 7 about here.]

\subsection{Theoretical background}

The computational cost of $C F D$ motivated investigation for the understanding and the assessment of the phenomena occurring in a diesel spray to simplify the calculation of spray flow-field development. Thus, different 1Dmodels have been proposed $[16,19,23]$ based on mixing-limited vaporization control, in which hypothesis made are the following: - The spray reaches the complete atomization regime very near the nozzle exit. - Local transfer rates of momentum, mass and energy between liquid droplets and surrounding air are fast in comparison to the rate of development of the flow field as a whole. This means that an a priori complicated two-phase problem is treated from the point of view of a single-phase flow where a fraction of fuel vaporizes instantaneously once there is enough enthalpy in the surrounding gas to heat it up and vaporize it. The appropriate mixture fraction where this energy 
balance is achieved is called $Y_{f, e v a p}$. Consequently, the liquid length, considered as the maximum liquid-phase penetration, could be defined as the position on the spray axis where this specific $Y_{f, e v a p}$ is reached. Following this hypothesis, a scaling law for liquid length has been derived [24] based on turbulent spray mixing considerations. The axial mass fraction within the quasi-steady part of a diesel spray could be obtained from:

$$
Y_{f}=K \cdot d_{0} \sqrt{\frac{\rho_{f}}{\rho_{\text {air }}}} \cdot \frac{1}{X}
$$

where K states for a spray constant, $d_{0}$ is nozzle diameter, $\rho_{f}$ and $\rho_{\text {air }}$ fuel and ambient density and $X$ is spray axial coordinate. Thus, liquid length is defined by:

$$
L L=K \cdot\left[d_{0} \sqrt{\frac{\rho_{f}}{\rho_{\text {air }}}}\right] \cdot \frac{1}{Y_{f, \text { evap }}}
$$

In Eqn. (2), the term in brackets is widely known in the literature as the equivalent diameter and is related to spray mixing scales (i.e momentum) while the last one, as stated before, is an energy term which takes into account vaporization processes. This last term could be written as in Eqn. (3), where $T_{\text {air }}$ is ambient gas temperature, $T_{f, 0}$ is the initial fuel temperature and $T_{\text {evap }}$ is the saturation temperature when the fuel is fully vaporized.

$$
\frac{1}{Y_{f, \text { evap }}}=1+\frac{\Delta h_{f}\left(T_{\text {evap }}, T_{f, 0}\right)}{\Delta h_{\text {air }}\left(T_{\text {air }}, T_{\text {evap }}\right)}
$$

This parameter shows a complex dependence on both fuel properties and ambient conditions $[16,24]$ such as air temperature, fuel specific and latent heat, and fuel initial temperature. 


\subsection{Statistical analysis}

These theoretical considerations have been applied in a statistical study in order to analyse experimental results and check hypotheses reliability. This study aims at relating liquid length with operating conditions and fuel characteristics. The following model for the dependence of liquid length has been proposed:

$$
L L \propto D_{\text {noz }}^{a} \cdot T_{\text {air }}^{b} \cdot P_{i n j}^{c} \cdot \rho_{\text {air }}^{d} \cdot \rho_{f}^{e} \cdot \nu_{f}^{f} \cdot T_{10 \%}^{g} \cdot T_{50 \%}^{h} \cdot T_{95 \%}^{i}
$$

The classical correlations for liquid length in diesel sprays have been completed with some factors particular to the fuel so that fuel fluid-mechanical and vaporizing properties are accounted. Coefficients b, c, d from Eqn. (4) have been previously evaluated independently for each fuel under both steady and unsteady conditions. Nozzle diameter effect has not been studied so $D_{n o z}^{a}$ and will be consequently part of the constant factor. Injection pressure exponent has been kept free, despite injection velocity (and thus injection pressure) has theoretically no influence on liquid length.

\subsection{Steady-State Conditions Approach}

The assumption of steady-state conditions has already been made by the authors in previous studies $[12,13]$ and so liquid length was considered to be constant around engine $T D C$ and resolve exponents from Eqn. (4) in terms of average values. A window for time-averaging is selected on the stabilized liquid-length region. The engine first-law thermodynamic analysis showed that the engine reaches $T_{\max }$ between -2.8 and $-3.1^{\circ} A T D C$ (4500 and $4625 \mu \mathrm{s} A S O E$ ) and $\rho_{\max }$ between -0.1 and $-0.5^{\circ} A T D C$ (5500 and 
$5625 \mu s$ ASOE), depending on the engine operating conditions. Therefore, time-averaging window has been limited between 3500 and $6500 \mu s$ ASOE. Figure 8 shows a plot of the ensemble average and its standard deviation. The section used for time-averaging has been highlighted and the result plotted in dashed line. Images from one of the ten corresponding sequences have been added for illustration. Only one image out of two has been displayed to simplify the figure.

[Figure 8 about here.]

Only the most relevant results of this analysis have been plotted in the Results and Discussion section but the whole set of numerical results is provided in an appendix table.

\subsection{In-Cylinder Unsteady Conditions Approach}

In order to check if both empirical models based on results obtained under steady-state conditions and spray models based on a succession of quasisteady evaporating states $[16,19]$ are extendable to real engine conditions, most of the image sequence has been exploited by attributing to each image of the spray its corresponding couple of $T_{\text {air }}$ and $\rho_{\text {air }}$ and resolve Eqn. (4) in terms of time-resolved values. As commented in the experimental apparatus description, the spray is exposed to important pressure variations. On Figure 5 , it can be observed how $T_{\text {air }}$ fluctuates over more than $50 \mathrm{~K}$ and so does $\rho_{\text {air }}$ by up to $7 \mathrm{~kg} \cdot \mathrm{m}^{-3}$ during the injection event $(\approx 24 \mathrm{CAD})$. This is due to the relative long injection timing $(8 \mathrm{~ms}$ ) compared to engine speed (500 rpm). Figure 8 shows how the in-cylinder pressure leaves its mark on the ensemble-averaged liquid length. Temperature and density time-derivatives 
have been plotted in Figure 9. It is worthy to note that despite the temporal variations seem to be small, they are of the order of expected variations in a heavy-duty engine at $1200 \mathrm{rpm}$ in the injection region for $\mathrm{HCCI}$ combustion mode and in the close-to- $T D C$ region for a conventional combustion mode. For this analysis, the time window used for analysis had also to be restricted to avoid the consideration of $S O I$ and EOI penetration transients. As an example, the case exposed in Figure 8, has been restricted between 1375 and $8875 \mu \mathrm{s} A S O E$. The liquid length results have been reprocessed using the same statistical method described above in order to assess the effect of air temperature and air density. From a statistical point of view, such kind of study is very interesting since it multiplies the combinations of $T_{a i r}$ and $\rho_{\text {air }}$. Moreover, blow-by, heat transfer and mechanical stresses induce a delay between both traces and reduce collinearity between both variables.

[Figure 9 about here.]

\section{Results and Discussion}

[Figure 10 about here.]

\subsection{Steady-State Conditions}

The liquid length at different injection pressures has been plotted for the five studied fuels in Figure 10. Significant differences can be observed from one fuel to another given the reduction by more than a factor of two between RME and FT2 liquid lengths. Both of these fuels constructed the upper and lower boundaries of the tested fuels, respectively. Figure 10 shows similar trends regarding two fuels encasing the others by upper and 
lower boundaries as in Figure 1, which illustrates the high influence of fuel volatility. Such result was then expected since the association between liquid length and distillation curves is already widely assumed in the literature $[3,10,4]$. The last works available on the subject still use this measurement to explain both the shorter FTD liquid length [20] and the higher biodiesel liquid length $[21,22]$ respective to the conventional diesel. A slight decrease of the liquid length can be observed among all the fuels when injection pressure is increased. However, this effect is small enough to consider this result in agreement with the "mixing-controlled" assumption. Although only the $\mathrm{NO}$-condition is represented, the same trends have been observed for the four other operating points. Since it has just been confirmed that injection pressure had no considerable effect on liquid-phase penetration, the effects of air temperature and air density have been represented only for the 150 $M P a$ injection pressure case in Figures 11 and 12. Again, the fuel hierarchy is conserved and is quite consistent with the distillation curves at ambient pressure. For all fuels, an increase on both air parameters leads to a reduction of the liquid length. Likewise, the effect of $T_{\text {air }}$ appears to be extremely significant. Indeed, a $13 \%$ increase of air temperature affects up to a $43 \%$ decrease on the liquid length, while a $36 \%$ increase of air density only decreases the liquid length by up to a $25 \%$. It must be highlighted that the $100 K$ variation applied in this study is far from covering the whole range of temperatures encountered in a diesel engine. Consequently, in early and late injection strategies, where the ambient temperature is expected to be even lower, the resulting liquid length, enhanced by the lower density as well, could lead to an important liner-impingement if care is not taken dur- 
ing the hardware design. The purpose of the following section is precisely to assess the weight of these parameters by means of the previously described statistical analysis.

[Figure 11 about here.]

[Figure 12 about here.]

\subsection{Statistical regression for engine-depending physical processes assessment}

In a first instance, the statistical analysis has been applied to each fuel independently, introducing only the parameters which change with the operating settings of the engine. In this way it is pretended to check if all fuels have the same sensitivity to engine parameters. $T_{a i r}, \rho_{a i r}$ and $P_{i n j}$ effect have been assessed and are presented in Table 5. Both temperature high impact and injection pressure irrelevance are confirmed while air density effect seems to be a bit higher than proposed by the scaling law. Moreover, from one fuel to the other, slight differences are appreciated, indicating a difference on fuel response to engine thermodynamic settings. Indeed, $R M E$ seems to be more gently affected by air conditions, way above the rest. If results from steady and unsteady-state are now considered for comparison, it can be observed that, exception made for $R M E$, the resulting exponents are remarkably close. It may be necessary to remind here that the "steady-state" exponents have been obtained using a set of averaged data coming from a sweep of three air density values at constant air temperature and from a sweep of three air temperature values at constant air density, both fueled at three injection pressures levels (15 values/fuel), while "unsteady state" considers air density and temperature values during the entire injection event 
for both sweeps $(\approx 900$ values/fuel). This parallelism in the results shows how a spray under unsteady conditions behaves as a succession of sprays obtained under steady-state conditions, meaning that there is no delay in the spray adjustment to its environment under the range of pressure derivatives studied. This result is in agreement with recent studies [25] and validates the use of theoretical $1 \mathrm{D}$ spray models $[16,19,23]$ in unsteady conditions as well as empirical models based on liquid length measurements obtained in a steady-state environment. Such conclusions are supported by the high correlations reliability that has been evaluated through the $\mathrm{R}$-squared parameter which is, apart for $R M E$, consistent between steady and unsteady state conditions.

The differences observed on exponents for $R M E$ as well as the decay observed on $R^{2}$ show that this fuel may not follow the same conclusions depicted above and that the characteristic time of vaporization for a droplet of such a dense, viscous and low volatility fuel may be significant compared to the spray flow field development. In [21], Fisher et al. performed a similar analysis as in [25] but using two biodiesel fuels. They also observed that biodiesel liquid length is not directly related to instantaneous in-cylinder temperature and density, and suggest that biodiesel may be subject to the thermodynamic history. An attempt has been made to quantify the biodiesel time-response. However the quality of the result showed to be highly affected by our relatively low camera frequency. Yet, no clear trends were found when this delay was correlated either with engine parameters or with the proper 
liquid length. Thus, both data and correlations were not robust enough to be presented in this manuscript and more investigation on the subject will be needed. Finally, liquid length results from all the fuels have been introduced to the statistical analysis simultaneously. As expected, if no dramatic effect can be observed on exponents' values, the very low $R^{2}$ shows that physical parameters issued from the engine setup are not sufficient to predict liquid length and that it is necessary to introduce fuel physical properties to achieve a better prediction.

\subsection{Statistical regression for fuel physics assessment}

The same statistical tool has been applied, introducing data from the measured fuel physical properties exposed in the upper corresponding section. They have been separated in 2 parts: fluid-mechanics and evaporative properties. Fluid-mechanics properties are represented by density and viscosity while evaporative properties, in absence of specific and latent heat, are represented by $T_{10 \%}, T_{50 \%}$ and $T_{95 \%}$ from distillation curves. Indeed, the purpose of the resulting correlations is to provide a tool that predicts liquid length out of cheap, off-engine measurements. A set of selected correlations are presented in Table 5 by using only some of the terms in Eqn. (4). In order to compare correlations with a different number of parameters, reliability has been calculated using specific R-squared $\left(R_{s p e}^{2}\right)$. As in the previous section, no significative differences have been observed between steady and unsteady-state considerations and therefore, only unsteady-state conditions are reported in Table 6. First, physical properties issued from the engine operation and fuel physical properties have been compared in correlations (1) and (2). It appears that fuel properties are more important than physi- 
cal in the prediction of liquid length. However negative coefficients for $T_{10 \%}$ and $T_{95 \%}$ are not physically reasonable. It is important then to identify, among the five physical parameters, which are controlling the process. In correlations (3) to (7), each fuel parameter has been associated to one physical parameters issue from the engine. Fuel density seems to be the best parameter for liquid length prediction, while no significant differences can be observed separating the 3 distillation curve temperatures. However the low $R^{2}$ for $T_{95 \%}$ is unacceptable. In correlations (8) and (9), the fuel fluid mechanics properties and fuel evaporative properties are respectively associated to engine physical properties. The result is that they are both good groups of variables for empirical modelling, although, again, the negative exponents for $T_{10 \%}$ and $T_{95 \%}$ are a physical non-sense. Finally, correlation (10) shows the association of both fluid-mechanics and evaporative properties using the most essential and reliable parameters. Correlation (11) has been added to show the maximum reliability these parameters are capable of, for comparison with upper correlations.

[Table 5 about here.]

\section{Summary and Conclusions}

Measurements of the maximum liquid-phase penetration have been performed using five fuels with an interesting potential for diesel substitution, in an optical engine under a large set of thermodynamic and injection conditions. These measurements have been related to fuel properties measurements performed off-engine and to pressure variations similar to those found 
in a heavy-duty diesel engine, in order to assess the physical processes controlling the vaporization of a spray under such conditions. Relevant conclusions are the following:

1. A database of fuel properties and time-averaged liquid-length results are provided for confrontation with modeling results (Cf. Appendix).

2. Under all tested conditions, Fischer-Tropsch fuels showed to have a shorter liquid length than biodiesel fuels, for which the liquid length was increased as the $R M E$ percentage was increased as well. The fuel hierarchy for liquid length was the following: FT2 $<F T 1<B 05<$ $B 30<R M E$. This trend was maintained for all engine settings.

3. The qualitative effects of $T_{a i r}, \rho_{a i r}$ and $P_{i n j}$ already available in the literature for diesel fuel have been confirmed and could be extended to biodiesel and Fischer-Tropsch fuels.

4. A new method, based on time consideration, has been proposed for the processing liquid length high speed imaging. It permitted to multiply the number of samples for a more robust statistical analisis.

5. For 4 out of the 5 tested fuels, the comparison between two statistical approaches showed that the spray liquid-phase adjust instantaneously to the in-cylinder conditions. Such results confirms the hypothesis made by $1 \mathrm{D}$ spray models and allows the use of empirical models obtained under steady-state environment in unsteady conditions (with time-derivatives up to $20000 \mathrm{~K} . \mathrm{s}^{-1}$ and $\left.2000 \mathrm{~kg} \cdot \mathrm{m}^{-3} . \mathrm{s}^{-1}\right)$.

6. Fuel physical properties have been assessed against the physical properties resulting from engine operating conditions and traduced into correlations for empirical modeling. 


\begin{tabular}{ccccc||ccccc||c}
\hline Fuel & $T_{\text {air }}$ & $\rho_{\text {air }}$ & $P_{i n j}$ & $\Delta P$ & $\rho_{f}$ & $\nu_{f}$ & $T_{10 \%}$ & $T_{50 \%}$ & $T_{95 \%}$ & $\mathrm{LL}$ \\
\hline B05 & 798.0 & 29.7 & 50 & 43.2 & 833 & 2.50 & 205 & 293 & 356 & 19.34 \\
& 798.0 & 29.7 & 100 & 93.2 & 833 & 2.50 & 205 & 293 & 356 & 18.42 \\
& 798.0 & 29.7 & 150 & 143.2 & 833 & 2.50 & 205 & 293 & 356 & 16.87 \\
& 845.2 & 25.8 & 50 & 43.7 & 833 & 2.50 & 205 & 293 & 356 & 17.83 \\
& 845.2 & 25.8 & 100 & 93.7 & 833 & 2.50 & 205 & 293 & 356 & 16.55 \\
& 845.2 & 25.8 & 150 & 143.7 & 833 & 2.50 & 205 & 293 & 356 & 15.84 \\
& 795.4 & 21.7 & 50 & 45.1 & 833 & 2.50 & 205 & 293 & 356 & 24.01 \\
& 795.4 & 21.7 & 100 & 95.1 & 833 & 2.50 & 205 & 293 & 356 & 22.68 \\
& 795.4 & 21.7 & 150 & 145.1 & 833 & 2.50 & 205 & 293 & 356 & 21.42 \\
& 747.5 & 25.9 & 50 & 44.5 & 833 & 2.50 & 205 & 293 & 356 & 25.64 \\
\hline
\end{tabular}

7. A correlation based on low cost off-engine measurements is proposed taking into account engine parameters, fuel fluid-mecanics properties and evaporation properties: $L L=T_{a i r}^{-2.63} \cdot P_{i n j}^{-0.06} \cdot \rho_{\text {air }}^{-0.60} \cdot \rho_{f}^{4.39} \cdot T_{50 \%}^{0.54}$

\section{Acknowledgment}

The authors wish to acknowledge the Spanish Ministry of Education and Science for the financial support through the OPTICOMB project (TRA200767961-C03-01). The authors would also like to thank Daniel Lerida for the management of the facility and his assistance in data acquisition.

[Table 6 about here.]

\section{Appendix}




\section{Appendix - continued from previous page}

\begin{tabular}{ccccc||ccccc||c}
\hline Fuel & $T_{\text {air }}$ & $\rho_{\text {air }}$ & $P_{\text {inj }}$ & $\Delta P$ & $\rho_{f}$ & $\nu_{f}$ & $T_{10 \%}$ & $T_{50 \%}$ & $T_{95 \%}$ & LL \\
\hline & 747.5 & 25.9 & 100 & 94.5 & 833 & 2.50 & 205 & 293 & 356 & 24.87 \\
& 747.5 & 25.9 & 150 & 144.5 & 833 & 2.50 & 205 & 293 & 356 & 22.90 \\
& 796.8 & 25.8 & 50 & 44.1 & 833 & 2.50 & 205 & 293 & 356 & 22.05 \\
& 796.8 & 25.8 & 100 & 94.1 & 833 & 2.50 & 205 & 293 & 356 & 20.17 \\
B05 & 796.8 & 25.8 & 150 & 144.1 & 833 & 2.50 & 205 & 293 & 356 & 19.07 \\
\hline \multirow{2}{*}{ B30 } & 798.0 & 29.7 & 50 & 43.2 & 849 & 3.10 & 223 & 304 & 347 & 24.53 \\
& 798.0 & 29.7 & 100 & 93.2 & 849 & 3.10 & 223 & 304 & 347 & 26.15 \\
& 798.0 & 29.7 & 150 & 143.2 & 849 & 3.10 & 223 & 304 & 347 & 24.28 \\
& 845.2 & 25.8 & 50 & 43.7 & 849 & 3.10 & 223 & 304 & 347 & 24.16 \\
& 845.2 & 25.8 & 100 & 93.7 & 849 & 3.10 & 223 & 304 & 347 & 23.07 \\
& 845.2 & 25.8 & 150 & 143.7 & 849 & 3.10 & 223 & 304 & 347 & 20.48 \\
& 795.4 & 21.7 & 50 & 45.1 & 849 & 3.10 & 223 & 304 & 347 & 30.58 \\
& 795.4 & 21.7 & 100 & 95.1 & 849 & 3.10 & 223 & 304 & 347 & 31.86 \\
& 795.4 & 21.7 & 150 & 145.1 & 849 & 3.10 & 223 & 304 & 347 & 31.17 \\
& 747.5 & 25.9 & 50 & 44.5 & 849 & 3.10 & 223 & 304 & 347 & 30.93 \\
& 747.5 & 25.9 & 100 & 94.5 & 849 & 3.10 & 223 & 304 & 347 & 32.08 \\
& 747.5 & 25.9 & 150 & 144.5 & 849 & 3.10 & 223 & 304 & 347 & 33.41 \\
& 796.8 & 25.8 & 50 & 44.1 & 849 & 3.10 & 223 & 304 & 347 & 28.49 \\
& 796.8 & 25.8 & 100 & 94.1 & 849 & 3.10 & 223 & 304 & 347 & 27.80 \\
\hline \multirow{2}{*}{ RME } & 796.8 & 25.8 & 150 & 144.1 & 849 & 3.10 & 223 & 304 & 347 & 26.03 \\
\hline & 798.0 & 29.7 & 100 & 93.2 & 878 & 4.41 & 321 & 334 & 345 & 29.57 \\
\hline
\end{tabular}




\section{Appendix - continued from previous page}

\begin{tabular}{ccccc||ccccc||c}
\hline Fuel & $T_{\text {air }}$ & $\rho_{\text {air }}$ & $P_{\text {inj }}$ & $\Delta P$ & $\rho_{f}$ & $\nu_{f}$ & $T_{10 \%}$ & $T_{50 \%}$ & $T_{95 \%}$ & LL \\
\hline & 798.0 & 29.7 & 150 & 143.2 & 878 & 4.41 & 321 & 334 & 345 & 30.20 \\
& 845.2 & 25.8 & 50 & 43.7 & 878 & 4.41 & 321 & 334 & 345 & 27.80 \\
& 845.2 & 25.8 & 100 & 93.7 & 878 & 4.41 & 321 & 334 & 345 & 27.57 \\
& 845.2 & 25.8 & 150 & 143.7 & 878 & 4.41 & 321 & 334 & 345 & 25.88 \\
& 795.4 & 21.7 & 50 & 45.1 & 878 & 4.41 & 321 & 334 & 345 & 39.14 \\
& 795.4 & 21.7 & 100 & 95.1 & 878 & 4.41 & 321 & 334 & 345 & 40.63 \\
& 795.4 & 21.7 & 150 & 145.1 & 878 & 4.41 & 321 & 334 & 345 & 39.36 \\
& 747.5 & 25.9 & 50 & 44.5 & 878 & 4.41 & 321 & 334 & 345 & 38.71 \\
& 747.5 & 25.9 & 100 & 94.5 & 878 & 4.41 & 321 & 334 & 345 & 45.85 \\
& 747.5 & 25.9 & 150 & 144.5 & 878 & 4.41 & 321 & 334 & 345 & 45.69 \\
& 796.8 & 25.8 & 50 & 44.1 & 878 & 4.41 & 321 & 334 & 345 & 36.73 \\
& 796.8 & 25.8 & 100 & 94.1 & 878 & 4.41 & 321 & 334 & 345 & 35.50 \\
RME & 796.8 & 25.8 & 150 & 144.1 & 878 & 4.41 & 321 & 334 & 345 & 34.03 \\
\hline FT1 & 798.0 & 29.7 & 50 & 43.2 & 784 & 3.44 & 250 & 297 & 352 & 18.26 \\
& 798.0 & 29.7 & 100 & 93.2 & 784 & 3.44 & 250 & 297 & 352 & 17.33 \\
& 798.0 & 29.7 & 150 & 143.2 & 784 & 3.44 & 250 & 297 & 352 & 16.12 \\
& 845.2 & 25.8 & 50 & 43.7 & 784 & 3.44 & 250 & 297 & 352 & 17.07 \\
& 845.2 & 25.8 & 100 & 93.7 & 784 & 3.44 & 250 & 297 & 352 & 15.90 \\
& 795.2 & 25.8 & 150 & 143.7 & 784 & 3.44 & 250 & 297 & 352 & 15.72 \\
& 21.7 & 50 & 45.1 & 784 & 3.44 & 250 & 297 & 352 & 22.31 \\
& 21.7 & 100 & 95.1 & 784 & 3.44 & 250 & 297 & 352 & 20.79 \\
& 21.7 & 150 & 145.1 & 784 & 3.44 & 250 & 297 & 352 & 20.08 \\
\hline
\end{tabular}




\section{Appendix - continued from previous page}

\begin{tabular}{ccccc||ccccc||c}
\hline Fuel & $T_{\text {air }}$ & $\rho_{\text {air }}$ & $P_{\text {inj }}$ & $\Delta P$ & $\rho_{f}$ & $\nu_{f}$ & $T_{10 \%}$ & $T_{50 \%}$ & $T_{95 \%}$ & LL \\
\hline & 747.5 & 25.9 & 50 & 44.5 & 784 & 3.44 & 250 & 297 & 352 & 23.28 \\
& 747.5 & 25.9 & 100 & 94.5 & 784 & 3.44 & 250 & 297 & 352 & 22.22 \\
& 747.5 & 25.9 & 150 & 144.5 & 784 & 3.44 & 250 & 297 & 352 & 20.92 \\
& 796.8 & 25.8 & 50 & 44.1 & 784 & 3.44 & 250 & 297 & 352 & 19.53 \\
& 796.8 & 25.8 & 100 & 94.1 & 784 & 3.44 & 250 & 297 & 352 & 18.48 \\
FT1 & 796.8 & 25.8 & 150 & 144.1 & 784 & 3.44 & 250 & 297 & 352 & 17.54 \\
\hline FT2 & 798.0 & 29.7 & 50 & 43.2 & 773 & 1.29 & 177 & 200 & 242 & 13.53 \\
& 798.0 & 29.7 & 100 & 93.2 & 773 & 1.29 & 177 & 200 & 242 & 13.09 \\
& 798.0 & 29.7 & 150 & 143.2 & 773 & 1.29 & 177 & 200 & 242 & 12.15 \\
& 845.2 & 25.8 & 50 & 43.7 & 773 & 1.29 & 177 & 200 & 242 & 13.08 \\
& 845.2 & 25.8 & 100 & 93.7 & 773 & 1.29 & 177 & 200 & 242 & 12.36 \\
& 845.2 & 25.8 & 150 & 143.7 & 773 & 1.29 & 177 & 200 & 242 & 11.70 \\
& 795.4 & 21.7 & 50 & 45.1 & 773 & 1.29 & 177 & 200 & 242 & 16.69 \\
& 795.4 & 21.7 & 100 & 95.1 & 773 & 1.29 & 177 & 200 & 242 & 15.92 \\
& 795.4 & 21.7 & 150 & 145.1 & 773 & 1.29 & 177 & 200 & 242 & 15.58 \\
& 747.5 & 25.9 & 50 & 44.5 & 773 & 1.29 & 177 & 200 & 242 & 18.75 \\
& 747.5 & 25.9 & 100 & 94.5 & 773 & 1.29 & 177 & 200 & 242 & 16.92 \\
& 747.5 & 25.9 & 150 & 144.5 & 773 & 1.29 & 177 & 200 & 242 & 15.94 \\
& 796.8 & 25.8 & 50 & 44.1 & 773 & 1.29 & 177 & 200 & 242 & 15.21 \\
\hline \hline & 796.8 & 25.8 & 100 & 94.1 & 773 & 1.29 & 177 & 200 & 242 & 13.77 \\
& 25.8 & 150 & 144.1 & 773 & 1.29 & 177 & 200 & 242 & 13.37 \\
\hline
\end{tabular}




\section{References}

[1] Browne KR, Partridge IM, Greeves G. Fuel Property Effects on Fuel/Air Mixing in an Experimental Diesel Engine. SAE Paper 860233; 1986

[2] Verhoeven D, Vanhemelryck JL, Baritaud T. Macroscopic and Ignition Characteristics of High-Pressures Sprays of Single-Component Fuels. SAE Paper 981069; 1998

[3] Canaan RE, Dec JE, Green RM, Daly DT. The Influence of Fuel Volatility on the Liquid-Phase Fuel Penetration in a Heavy-Duty D.I. Diesel Engine. SAE Paper 980510; 1998

[4] Higgins BS, Mueller CJ, Siebers D. Measurements of Fuel Effects on Liquid-Phase Penetration in DI Sprays, SAE Paper 1999-01-0519; 1999

[5] Official Journal of the European Union, Directive 2003/30/EC of the European parliament and of the council of 8 May 2003 on the promotion of the use of biofuels or other renewable fuels for transport.

[6] Beatrice C, Guido C, Di Iorio S. Experimental analysis of alternative fuel impact on a new torque-controlled light-duty diesel engine for passenger cars. Fuel, 89:32783286; 2010

[7] Bermúdez V, García JM, Juliá E, Martínez S. Engine with Optically Accessible Cylinder Head: a Research Tool for Injection and Combustion Processes. SAE Paper 2003-01-1110; 2003

[8] Design and Operation of a High Pressure, High Temperature Cell for HD Diesel Spray Diagnostics: Guidelines and Results. Baert RSG, Frijters 
PJM, Somers B, Luijten CCM, de Boer W. SAE Paper 2009-01-0649; 2009

[9] Dec JE, Espey C. The Effect of Tdc Temperature and Density on the Liquid-Phase Fuel Penetration in a D.I. Diesel Engine. SAE Trans., 104(4):1400-1414; 1995

[10] Siebers DL. Liquid-Phase Fuel Penetration in diesel Sprays, SAE Trans., 107(3):1205-1227; 1998

[11] Payri R, Salvador FJ, Gimeno J, Zapata LD. Diesel nozzle geometry influence on spray liquid-phase fuel penetration in evaporative conditions. Fuel,87(7):1165-1176; 2008

[12] Pastor JV, Pastor JM, Gimeno J, Nerva J-G. The effect of Biodiesel fuel blend rate on the Liquid-phase fuel penetration in Diesel engine conditions, SAE Paper 2009-24-0051; 2009

[13] Pastor JV, Payri R, Gimeno J, Nerva J-G. Experimental Study on RME Blends: Liquid-Phase Fuel Penetration, Chemiluminescence, and Soot Luminosity in Diesel-Like Conditions. Energy Fuels, 23(12):5899-5915; 2009

[14] Klein-Douwel RJH, Frijters PJM, Somers LMT, de Boer WA, Baert RSG. Macroscopic diesel fuel spray shadowgraphy using high speed digital imaging in a high pressure cell. Fuel 86:19942007; 2007

[15] Allocca L, Mancaruso E, Montanaro A, Sequino L, Vaglieco BM. Effects of mineral and biodiesel fuel compositions on spray evolution and mixture distribution. THIESEL Conference. Valencia, Spain; 2010 
[16] Siebers DL. Scaling Liquid-Phase Fuel Penetration in diesel Sprays Based on Mixing - Limited Vaporization, SAE Trans., 108(3):703-728; 1999

[17] Pastor JV, Arrègle J, Palomares A. Diesel spray image segmentation with a likelihood ratio test. Applied Optics, 40:1-10; 2001

[18] Pastor JV, Arrègle J, García JM, Zapata LD. Segmentation of Diesel spray images with loglikelihood ratio test algorithm for non-Gaussian distributions. Applied Optics, 46(6):888-899; 2007

[19] Pastor JV, López JJ, García JM, Pastor JM. A 1D model for the description of mixing-controlled inert diesel sprays. Fuel, 87(13-14):2871-2885; 2008

[20] Azimov U, Kim KS. Visualization of Gas-to-Liquid (GTL) Fuel Liquid Length and Soot Formation in the Constant Volume Combustion Chamber. Journal of Thermal Science and Technology, 3:461-473; 2008

[21] Fisher BT, Knothe G, Mueller CJ. Liquid-Phase Penetration under Unsteady In-Cylinder Conditions: Soy- and Cuphea-Derived Biodiesel Fuels Versus Conventional Diesel. Energy Fuels, 24:51635180; 2010

[22] Genzale CL, Pickett LM, Kook S, Liquid Penetration of Diesel and Biodiesel Sprays at Late-Cycle Post-Injection Conditions. SAE Paper 2010-01-0610; 2010

[23] Musculus MPB, Kattke K. Entrainment Waves in Diesel Jets, SAE Int. J. Engines 2:1170-1193; 2009 
[24] Desantes JM, Pastor JV, Payri R, Pastor JM. Experimental characterization of internal nozzle flow and diesel spray behavior. Part II. Evaporative conditions. Atomization and Sprays, 15:517-543; 2005

[25] Fisher BT, Mueller CJ. Liquid penetration length of heptamethylnonane and trimethylpentane under unsteady in-cylinder conditions. Fuel, 89:2673-96; 2010 


\section{List of Figures}

1 Distillation curves obtained by $A S T M$ D86. . . . . . . . . . . 30

2 Temperature effect on fuel density under atmospheric pressure. 31

3 Hot spray test rig and diffuse back-lightening optical setup. . . 32

4 Cutaway view of the injector tip. . . . . . . . . . . . 33

5 Schematic representation of the engine operating conditions. . 34

6 Results of in-cylinder first-law thermodynamic analysis for temperature and density calculation in the $T D C$ region. 8 $m s$ energizing time is represented by the injector current. . . . 35

$7 \quad$ Intermediate processing images from FT2 at BT and $P_{i n j}=100$ $M P a$. (a) Resulting image from original image subtraction to the background. (b) Overlay of the boundary resulting from the complete processing to the original image. . . . . . . . . 36

8 Representation of the cycle-to-cycle averaging and standard deviation (from 10 repetitions) for FT1, Low Density $\left(22 \mathrm{~kg} \cdot \mathrm{m}^{-3}\right.$ ; $800 \mathrm{~K}$ ) at $50 \mathrm{MPa}$ injection pressure. Images (1 out of 2) from one cycle have been added for illustration. The timeaveraging window (3500 to $6500 \mu \mathrm{s} A S O E$ ) is represented in green and the time-averaged value dashed blue line. $\rho_{\text {air }}(t)$ and $T_{\text {air }}(t)$ are represented in the upper part of the figure. . . 37

9 Temperature and density time-derivatives during the injection event. . . . . . . . . . . . . . . . . 38

10 Injection pressure effect on liquid length for the five studied fuels at NO air conditions. . . . . . . . . . . . . . . . . 39

11 Air density effect on liquid length for the five studied fuels at 150 MPa injection pressure. . . . . . . . . . . . 40

12 Air temperature effect on liquid length for the five studied fuels at $150 \mathrm{MPa}$ injection pressure. . . . . . . . . . . 41 


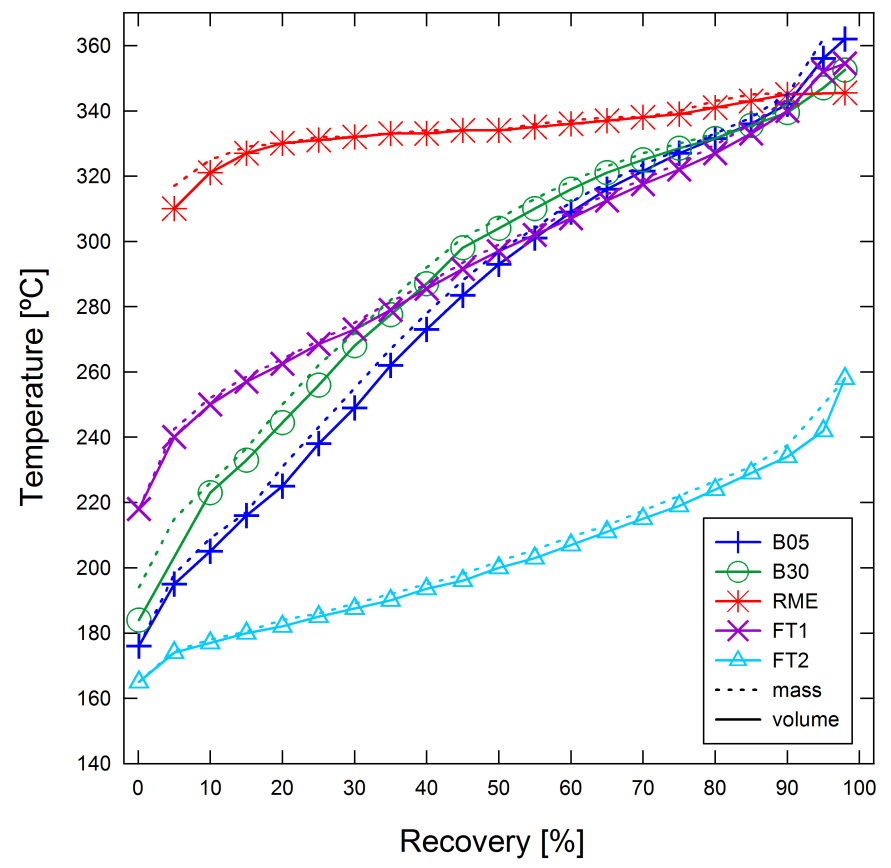

Figure 1: Distillation curves obtained by $A S T M D 86$. 


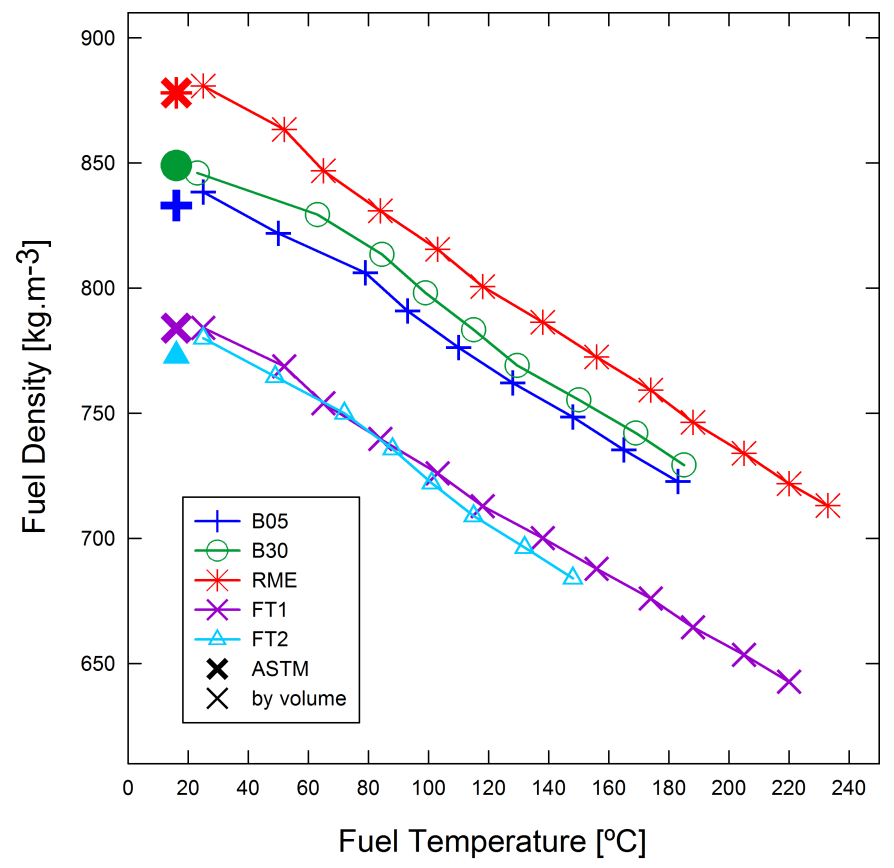

Figure 2: Temperature effect on fuel density under atmospheric pressure. 


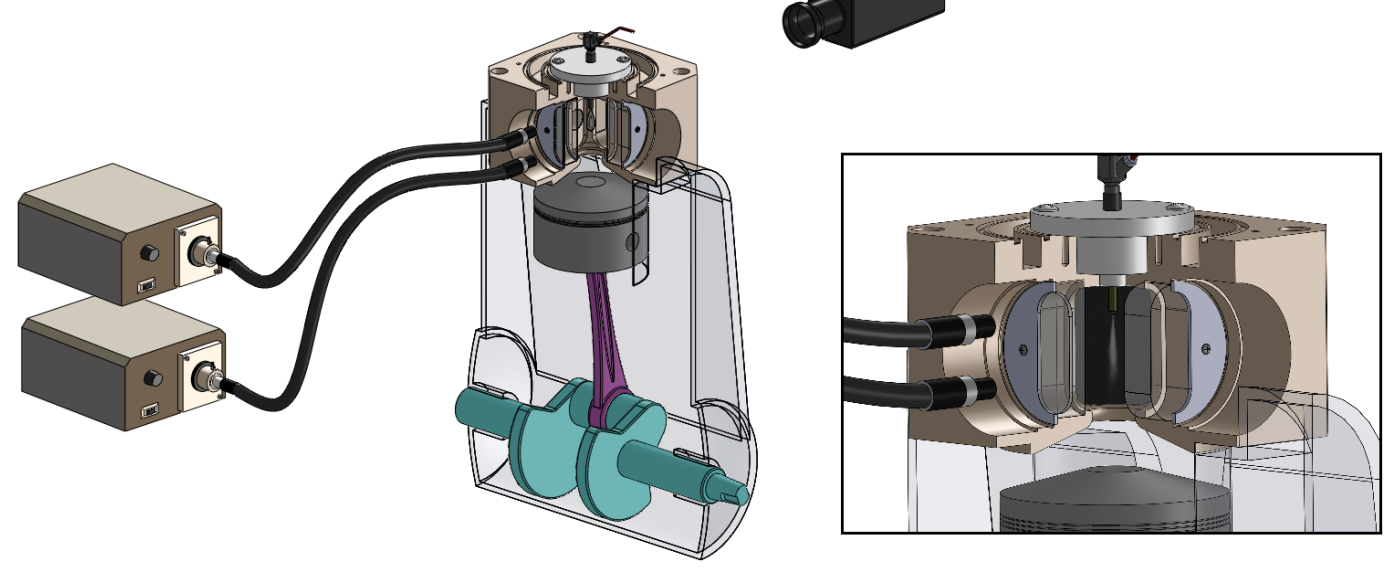

Figure 3: Hot spray test rig and diffuse back-lightening optical setup. 


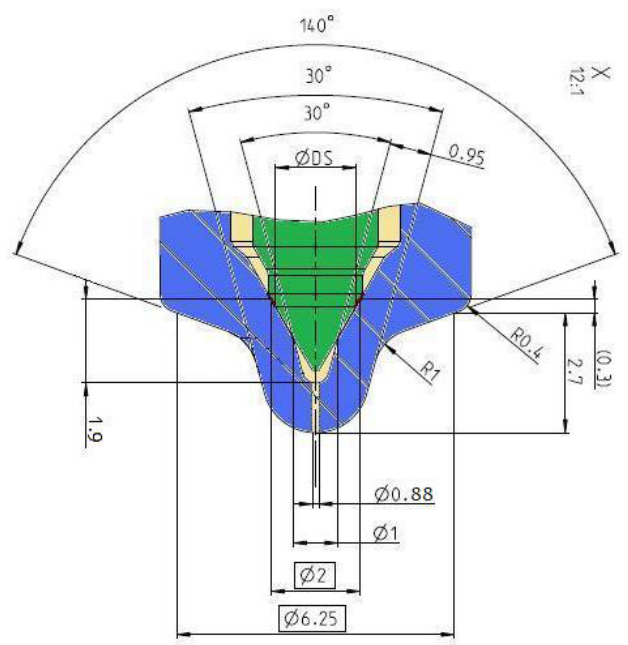

Figure 4: Cutaway view of the injector tip. 


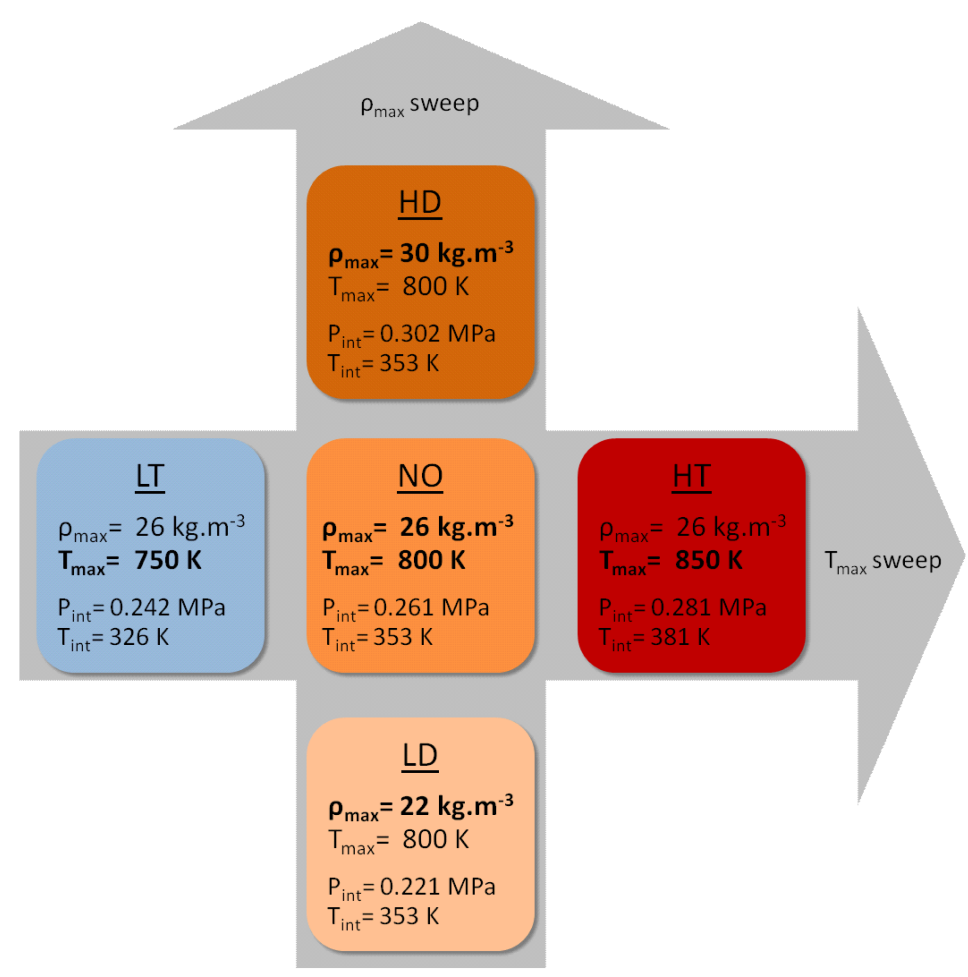

Figure 5: Schematic representation of the engine operating conditions. 


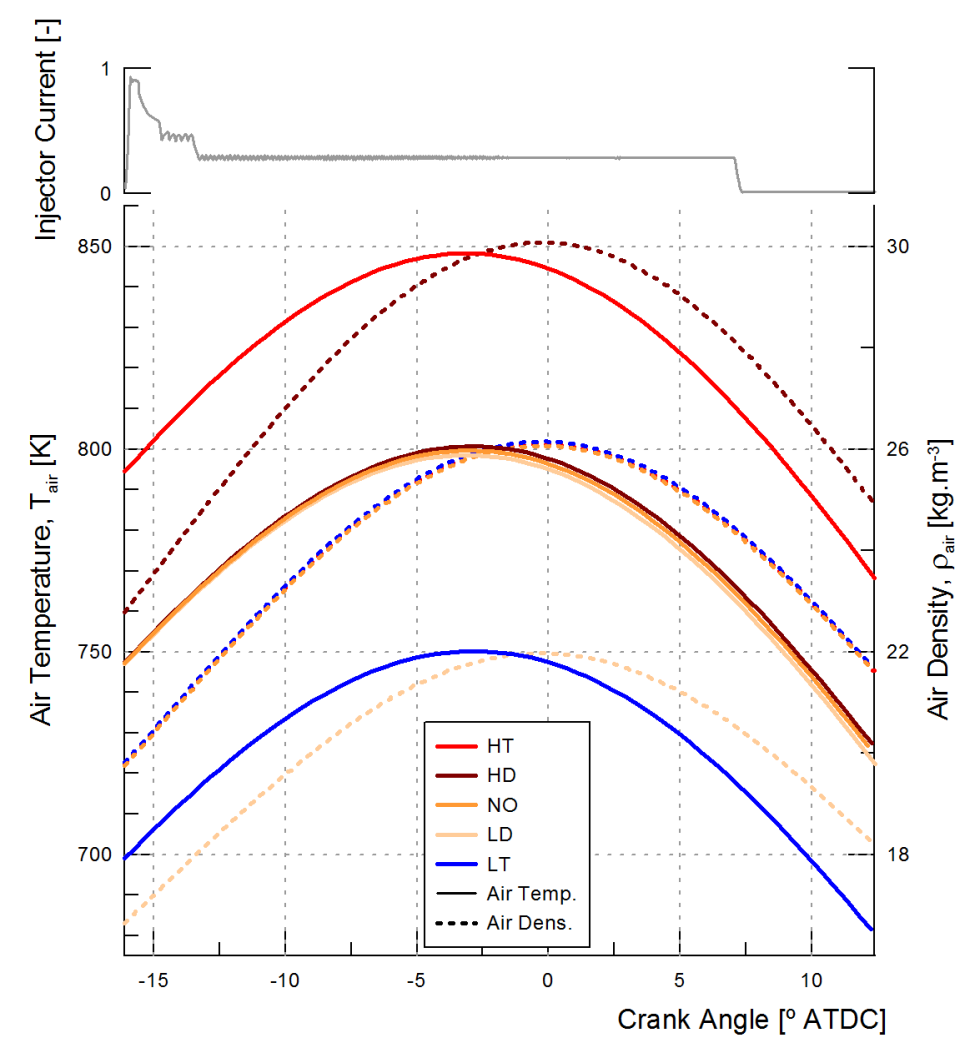

Figure 6: Results of in-cylinder first-law thermodynamic analysis for temperature and density calculation in the $T D C$ region. $8 \mathrm{~ms}$ energizing time is represented by the injector current. 


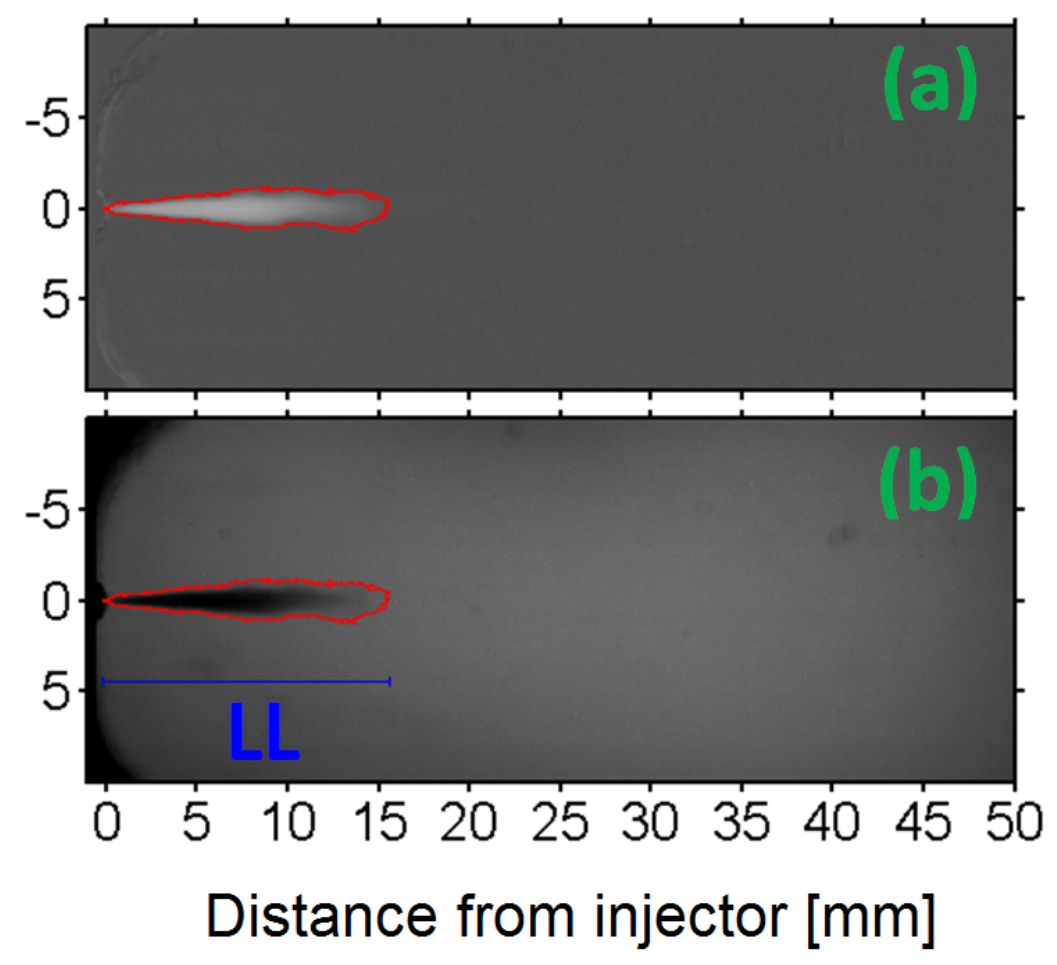

Figure 7: Intermediate processing images from FT2 at BT and $P_{i n j}=100 \mathrm{MPa}$. (a) Resulting image from original image subtraction to the background. (b) Overlay of the boundary resulting from the complete processing to the original image. 


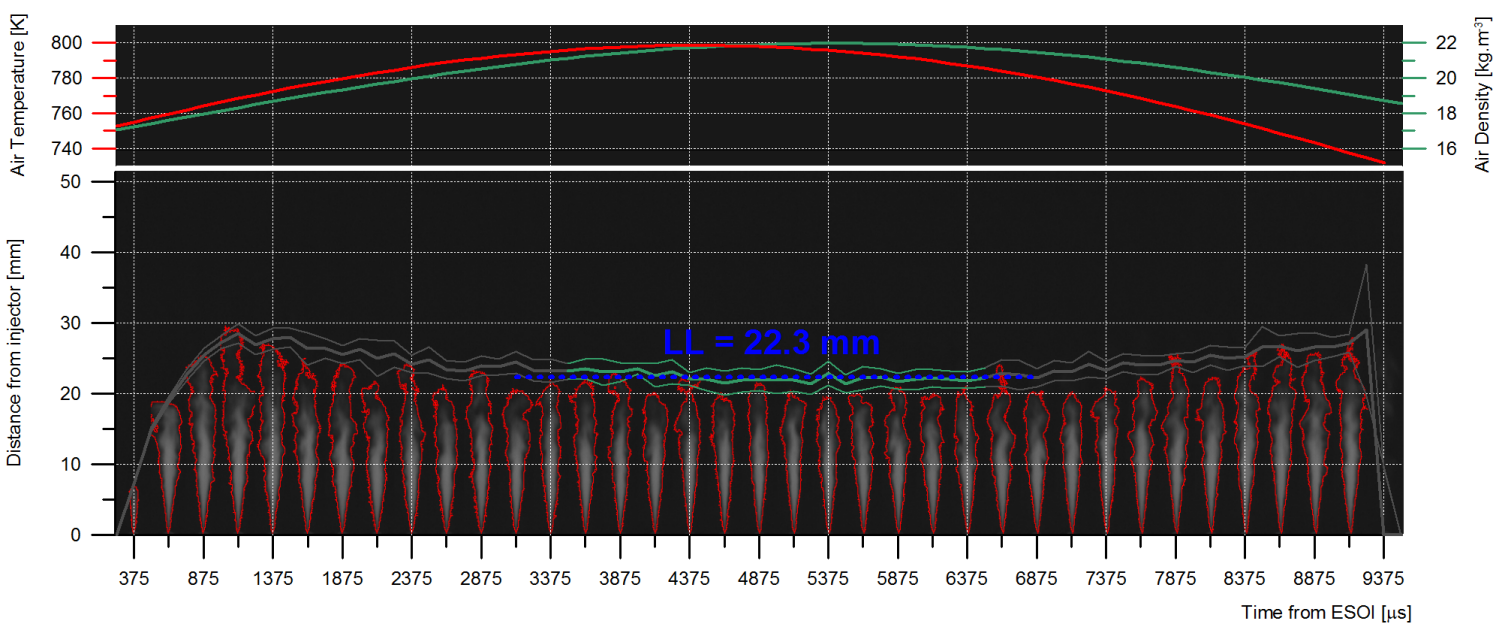

Figure 8: Representation of the cycle-to-cycle averaging and standard deviation (from 10 repetitions) for $F T 1$, Low Density $\left(22 \mathrm{~kg} \cdot \mathrm{m}^{-3} ; 800 \mathrm{~K}\right)$ at $50 \mathrm{MPa}$ injection pressure. Images ( 1 out of 2 ) from one cycle have been added for illustration. The time-averaging window (3500 to $6500 \mu \mathrm{s} A S O E$ ) is represented in green and the time-averaged value dashed blue line. $\rho_{\text {air }}(t)$ and $T_{\text {air }}(t)$ are represented in the upper part of the figure. 


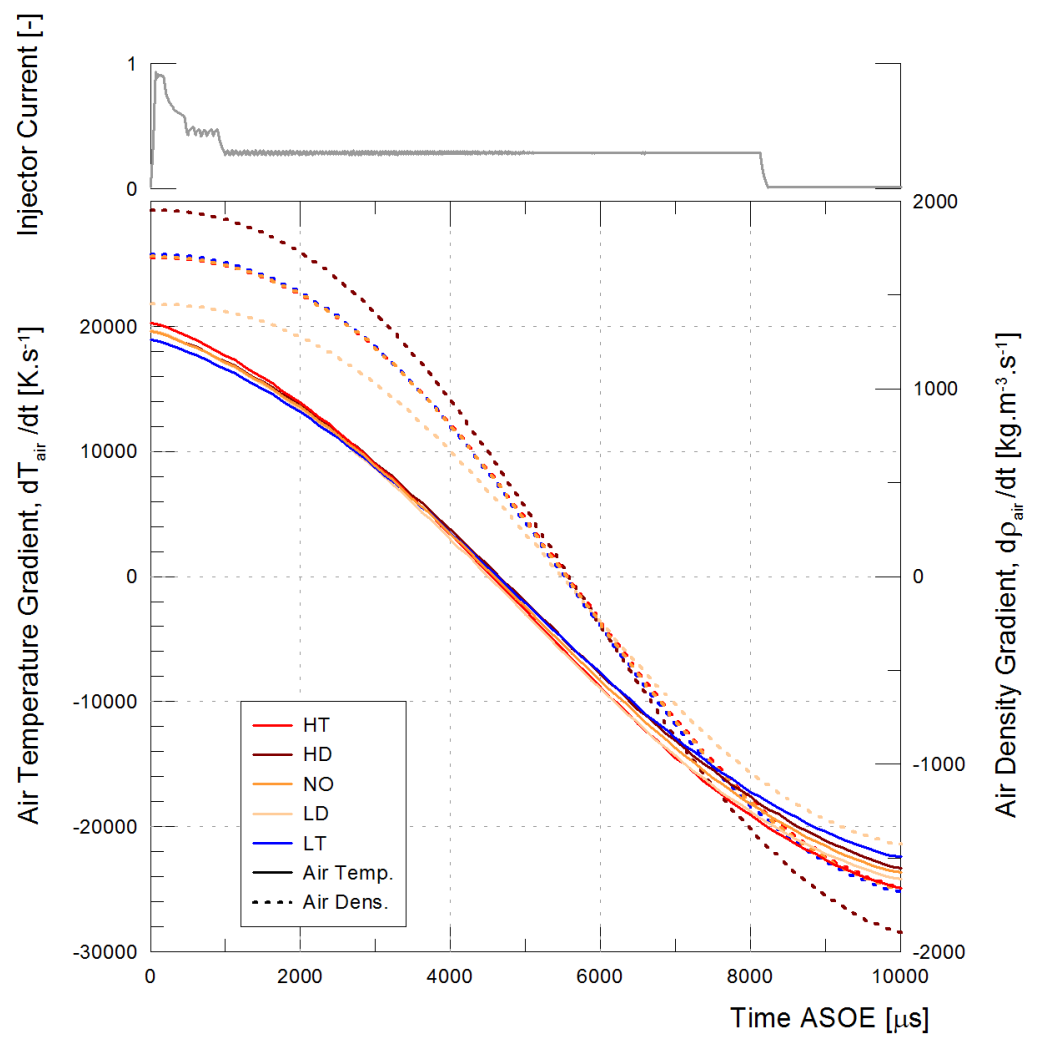

Figure 9: Temperature and density time-derivatives during the injection event. 


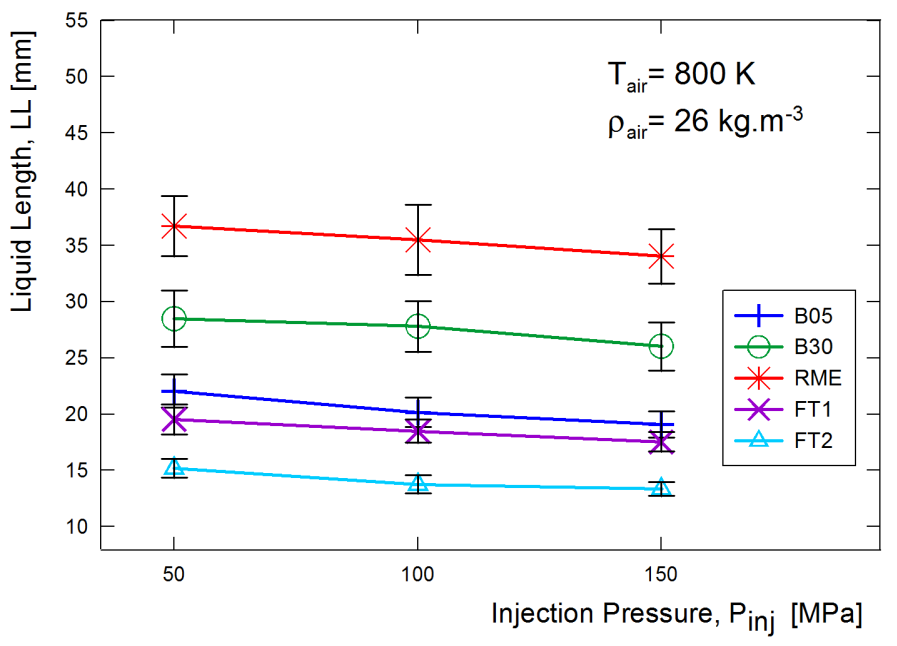

Figure 10: Injection pressure effect on liquid length for the five studied fuels at NO air conditions. 


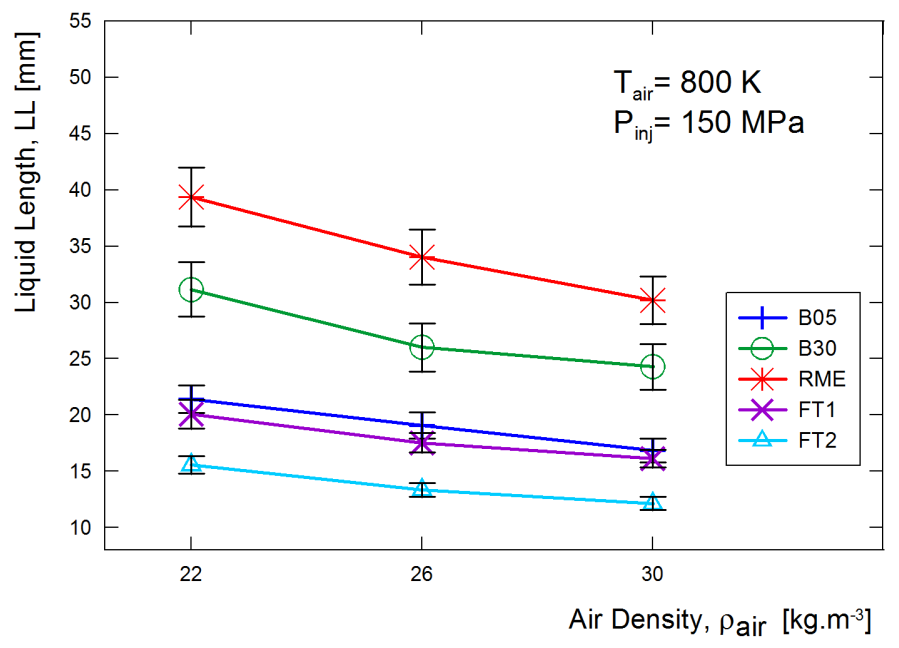

Figure 11: Air density effect on liquid length for the five studied fuels at $150 \mathrm{MPa}$ injection pressure. 


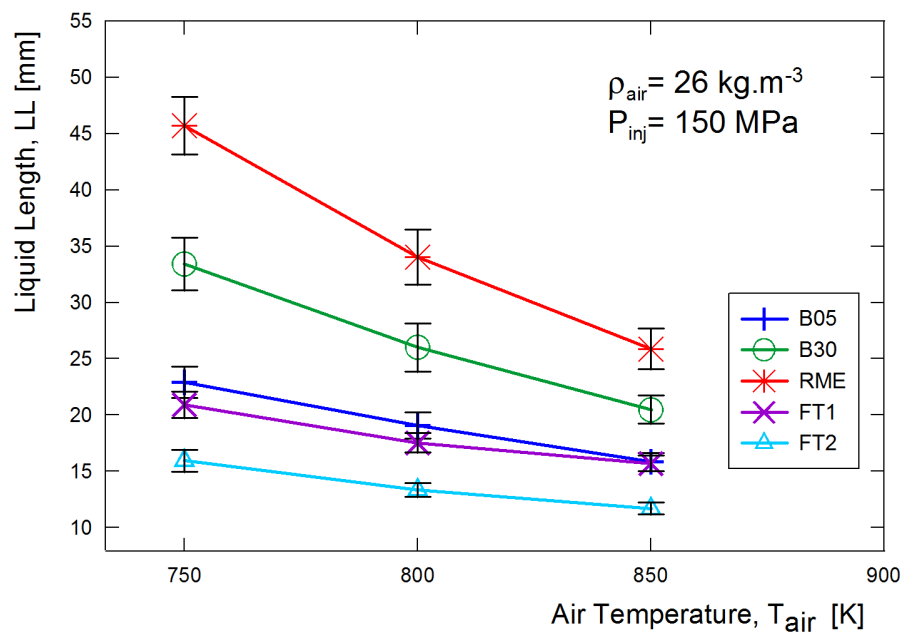

Figure 12: Air temperature effect on liquid length for the five studied fuels at $150 \mathrm{MPa}$ injection pressure. 


\section{List of Tables}

2 Fuel relevant properties. . . . . . . . . . . . . . . . . . 43

3 Linear regression coefficients for fuel density dependency to temperature $\left(\rho_{f}=B+A \cdot T_{f}\right) \ldots \ldots . \ldots . \ldots 44$

4 Injector characteristics. . . . . . . . . . . . . . . 45

5 Results from the statistical analysis for assessment of engine physical conditions under both steady and unsteady-conditions. Non-significative exponents ( $\mathrm{p}$-value $>0.05$ ) appear in grey. . . 46

6 Results from the statistical analysis for assessment of engine physical conditions and fuel physical properties under unsteadystate conditions. . . . . . . . . . . . . . . . 47 Nomenclature . . . . . . . . . . . . . . . . . 48 
Table 2: Fuel relevant properties.

\begin{tabular}{|c|c|c|c|c|c|c|c|}
\hline Fuels Properties & Unit & $A S T M S t c$ & $\mathrm{~B} 05$ & B30 & RME & FT1 & FT2 \\
\hline Density & {$\left[k g \cdot m^{-3}\right]$} & D1298 & 833 & 849 & 878 & 784 & 773 \\
\hline Kinematic Viscosity & {$\left[m m^{2} \cdot s^{-1}\right]$} & $D 445$ & 2.5 & 3.1 & 4.4 & 3.4 & 1.3 \\
\hline Lower Heating Value & {$\left[M J . \mathrm{kg}^{-1}\right]$} & D240 & 42.11 & 41.77 & 38.24 & 44.76 & 44.24 \\
\hline $\begin{array}{l}\text { Equivalent Chemical } \\
\text { Formula }\end{array}$ & - & D5291 & - & - & $\mathrm{C}_{18.95} \mathrm{H}_{35.2} \mathrm{O}_{2}$ & $\mathrm{C}_{17} \mathrm{H}_{35.5}$ & $\mathrm{C}_{12} \mathrm{H}_{25} \mathrm{O}_{0.2}$ \\
\hline $\mathrm{C} / \mathrm{H}$ ratio & - & - & - & - & 0.538 & 0.479 & 0.480 \\
\hline$A / F_{s t}\left(20.9 \% X O_{2}\right)$ & - & - & - & - & 12.398 & 14.748 & 14.388 \\
\hline
\end{tabular}


Table 3: Linear regression coefficients for fuel density dependency to temperature ( $\rho_{f}=B+A \cdot T_{f}$.

\begin{tabular}{lccccc}
\hline Coefficients & B05 & B30 & RME & FT1 & FT2 \\
\hline A & -0.747 & -0.759 & -0.815 & -0.726 & -0.804 \\
B & 859.5 & 871.2 & 900.6 & 801.8 & 803.6 \\
$R^{2}$ & $99.8 \%$ & $99.4 \%$ & $99.8 \%$ & $99.8 \%$ & $99.4 \%$ \\
\hline
\end{tabular}


Table 4: Injector characteristics.

\begin{tabular}{ll}
\hline Injector & \\
\hline Injector Type & Bosch Solenoid \\
Nozzle Type & Mini-Sac \& Single Hole \\
Nozzle Diameter (Nominal/Measured) & $80 / 82 \mu \mathrm{m}$ \\
Nozzle Conicity & $\mathrm{K} 1.5$ \\
Energizing duration & $8 \mathrm{~ms}$ \\
Injection pressures & $50,100,150 \mathrm{MPa}$ \\
\hline
\end{tabular}


Table 5: Results from the statistical analysis for assessment of engine physical conditions under both steady and unsteady-conditions. Non-significative exponents (p-value $>0.05$ ) appear in grey.

\begin{tabular}{|c|c|c|c|c|c|c|c|c|}
\hline $\begin{array}{l}\text { Parameter } \\
\text { Exponents } \\
\text { Theoretical }\end{array}$ & & $\begin{array}{c}\text { Cte } \\
- \\
-\end{array}$ & $\begin{array}{c}d_{0} \\
\mathrm{a} \\
1\end{array}$ & $\begin{array}{c}T_{a i r} \\
\mathrm{~b} \\
-1.58\end{array}$ & $\begin{array}{c}P_{i n j} \\
\mathrm{c} \\
0\end{array}$ & $\begin{array}{c}\rho_{\text {air }} \\
\mathrm{d} \\
-0.5\end{array}$ & $\begin{array}{c}- \\
R^{2} \\
-\end{array}$ & $\begin{array}{c}- \\
\text { RMSE } \\
-\end{array}$ \\
\hline B05 & & $0324 \mathrm{E}+11$ & - & -3.11 & 0.10 & -0.68 & 99. & 0.28 \\
\hline B3 & & $3.7266 \mathrm{E}$ & - & -2.80 & -0.02 & -0.70 & 92. & 0.91 \\
\hline RME & & $3.2664 \mathrm{E}+15$ & - & -4.39 & -0.04 & -0.82 & 99. & 0.59 \\
\hline FT1 & శో & $5.3889 \mathrm{E}+09$ & - & -2.55 & -0.09 & -0.63 & 99. & 0.19 \\
\hline FT2 & 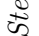 & $1.1733 \mathrm{E}+10$ & - & -2.68 & -0.10 & -0.67 & 97.9 & 0.26 \\
\hline All fuels & & $1.2095 \mathrm{E}+1$ & - & -2.98 & -0.06 & -0.69 & 15.3 & 6.95 \\
\hline & & $0120 \mathrm{~F}+1$ & & -3.12 & & -0.6 & 96 & 0.60 \\
\hline & & $3.9238 \mathrm{E}$ & - & -2.81 & -0.02 & -0.69 & 89. & 1.23 \\
\hline $\mathrm{RMH}$ & & 7.92 & - & -3.55 & -0.01 & -0.75 & 88.9 & 2.02 \\
\hline & & 4.4816 & - & -2.54 & -0.09 & -0.60 & 97.4 & 0.43 \\
\hline FT2 & & 3. & 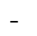 & -2.53 & -0.09 & -0.58 & 95.5 & 0.44 \\
\hline All fuels & & $9.9393 \mathrm{E}+08$ & 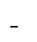 & -2.42 & -0.05 & -0.39 & 11.3 & 6.82 \\
\hline
\end{tabular}


Table 6: Results from the statistical analysis for assessment of engine physical conditions and fuel physical properties under unsteady-state conditions.

\begin{tabular}{|c|c|c|c|c|c|c|c|c|c|c|c|c|c|c|}
\hline $\begin{array}{l}\text { Parameter } \\
\text { Exponents } \\
\text { Theoretica }\end{array}$ & & $\#$ & $\begin{array}{c}\text { Cte } \\
- \\
-\end{array}$ & $\begin{array}{c}d_{0} \\
\mathrm{a} \\
1\end{array}$ & $\begin{array}{c}T_{a i r} \\
\mathrm{~b} \\
-1.58\end{array}$ & $\begin{array}{c}P_{i n j} \\
\mathrm{c} \\
0\end{array}$ & $\begin{array}{c}\rho_{\text {air }} \\
\mathrm{d} \\
-0.5\end{array}$ & $\begin{array}{c}\rho_{f} \\
\mathrm{e} \\
0.5\end{array}$ & $\begin{array}{l}\nu_{f} \\
\mathrm{f} \\
-\end{array}$ & $\begin{array}{c}T_{10 \%} \\
\mathrm{~g} \\
-\end{array}$ & $\begin{array}{c}T_{50 \%} \\
\mathrm{~h} \\
-\end{array}$ & $\begin{array}{c}T_{95 \%} \\
\mathrm{i} \\
-\end{array}$ & $\begin{array}{c}R_{\text {spe }}^{2} \\
-\end{array}$ & $\begin{array}{c}- \\
\text { RMSE }\end{array}$ \\
\hline \multirow{11}{*}{ All fuels } & \multirow{11}{*}{ 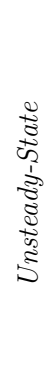 } & (1) & $9.9393 \mathrm{E}+08$ & - & -2.42 & -0.05 & -0.39 & - & - & - & - & - & 11.3 & 6.82 \\
\hline & & (2) & $1.0000 \mathrm{E}+00$ & - & - & - & - & 0.71 & 0.22 & -1.14 & 5.41 & -4.53 & 78.2 & 3.45 \\
\hline & & (3) & $8.2699 \mathrm{E}-08$ & - & -2.78 & -0.06 & -0.61 & 5.99 & - & - & - & - & 88.7 & 2.57 \\
\hline & & (4) & $6.8209 \mathrm{E}+09$ & - & -2.72 & -0.06 & -0.55 & - & 0.62 & - & - & - & 79.5 & 3.15 \\
\hline & & (5) & $9.4517 \mathrm{E}+06$ & - & -2.68 & -0.06 & -0.54 & - & - & 1.27 & - & - & 75.1 & 3.80 \\
\hline & & (6) & $3.2668 \mathrm{E}+06$ & - & -2.66 & -0.06 & -0.54 & - & - & - & 1.39 & - & 69.0 & 4.10 \\
\hline & & (7) & $1.5327 \mathrm{E}+06$ & - & -2.51 & -0.06 & -0.47 & - & - & - & - & 1.27 & 45.4 & 5.01 \\
\hline & & (8) & $2.2874 \mathrm{E}-03$ & - & -2.74 & -0.06 & -0.61 & 4.39 & 0.26 & - & - & - & 94.6 & 1.62 \\
\hline & & (9) & $1.8131 \mathrm{E}+10$ & - & -2.85 & -0.07 & -0.63 & - & - & -1.23 & 6.94 & -5.45 & 97.9 & 0.97 \\
\hline & & (10) & $6.1213 \mathrm{E}-05$ & - & -2.63 & -0.06 & -0.60 & 4.39 & - & - & 0.54 & - & 94.4 & 1.57 \\
\hline & & (11) & $1.0000 \mathrm{E}+00$ & - & -2.85 & -0.07 & -0.63 & 6.61 & 1.70 & -0.90 & -2.89 & -0.06 & 98.1 & 0.93 \\
\hline
\end{tabular}


Table 7: Nomenclature

\begin{tabular}{|c|c|}
\hline B05/B30 & Fossil diesel with $5 \% / 30 \%$ RME (in mass) \\
\hline RME & Rapeseed Methyl-Ester \\
\hline FT(D) & Fischer-Tropsch (Diesel) \\
\hline $\mathrm{LD} / \mathrm{HD}$ & Low/High Density condition (at $800 \mathrm{~K}$ ) \\
\hline $\mathrm{LT} / \mathrm{HT}$ & Low/High Temperature condition (at $26 \mathrm{~kg} \cdot \mathrm{m}^{-3}$ ) \\
\hline NO & Nominal condition \\
\hline $\mathrm{OC}$ & Operating Conditions \\
\hline \multicolumn{2}{|l|}{ Subscripts } \\
\hline 0 & relative to initial conditions \\
\hline $\mathrm{f}$ & fuel \\
\hline air & relative to the air surrounding the spray \\
\hline inj & injection \\
\hline $\max$ & maximum \\
\hline evap & evaporation \\
\hline back & relative to the spray counter-pressure \\
\hline \multicolumn{2}{|l|}{ Abbreviations } \\
\hline $\mathrm{P}$ & pressure \\
\hline$\Delta P$ & pressure drop $=P_{i n j}-P_{b a c k}$ \\
\hline $\mathrm{T}$ & temperature \\
\hline$\rho$ & density \\
\hline $\mathrm{h}$ & enthalpy \\
\hline K & constant value \\
\hline $\mathrm{X}$ & spray axis \\
\hline Y & mixture fraction \\
\hline LL & Liquid Length \\
\hline & One-dimensional \\
\hline $\begin{array}{l}\text { (A)SOI/E, EOI } \\
\text { (A)TDC }\end{array}$ & $\begin{array}{l}\text { (after) start of injection/energizing, end of injection } \\
\text { (After) Top Dead Center }\end{array}$ \\
\hline ASTM & American society for testing and materials \\
\hline CAD & crank angle degree \\
\hline CFD & computational fluid dynamics \\
\hline CMOS & complementary metal-oxide semiconductor \\
\hline EGR & Exhaust Gas Recirculation \\
\hline FID & flame ionization detector \\
\hline $\mathrm{HCCI}$ & homogeneous charge compression ignition \\
\hline LHV & Lower Heating Value $\left[M J . \mathrm{kg}^{-1}\right]$ \\
\hline$N O_{X}$ & mono-nitrogen oxides \\
\hline $\mathrm{PM}$ & particulate Matter \\
\hline $\mathrm{rpm}$ & revolutions per minute \\
\hline$R_{(\text {spe })}^{2}$ & (specific) coefficient of determination \\
\hline RMSE & root mean square error \\
\hline TTL & transistor-transistor logic \\
\hline
\end{tabular}

